\title{
CONSTRUÇÃO DE PARÁFRASES: UMA FORMA DE APROPRIAÇÃO GENUÍNA DE SIGNIFICADOS NO ENSINO DE ECOLOGIA
}

\author{
Lucas Roberto Perucci \\ Instituto Federal do Paraná \\ Capanema, Paraná \\ E-mail: lucas.perucci@ifpr.edu.br

\section{Carlos Eduardo Laburú} \\ Universidade Estadual de Londrina \\ Londrina, Paraná \\ E-mail: laburu@elu.br
}

Resumo: O trabalho apresenta uma estratégia de ensino de Biologia que se utiliza da paráfrase para promover apropriações dos conceitos de energia e matéria dos ecossistemas. A paráfrase é defendida como uma forma de apropriação autônoma e singular do discurso pelo aprendiz, frente uma proposição científica original de modo a guardar correspondência de significado. A base teórica do artigo se sustenta em elementos da teoria da semiologia voltados para a educação científica, com foco no registro escrito da língua. Uma unidade didática foi elaborada e aplicada com estudantes do terceiro ano do ensino médio na disciplina de Biologia, nos conteúdos de matéria e energia de ecossistemas, em três aulas. As paráfrases foram produzidas por cinco estudantes e no presente artigo é analisada a produção de dois deles. Resultados indicam que a estratégia de ensino proposta pode evidenciar o repertório do estudante em conceitos-chave em ciências, com a reelaboração dos conteúdos pela paráfrase. A atividade permite estabelecer critérios para que aprendizes evitem respostas estereotipadas e potencialize apropriações de enunciados-chave dos conceitos científicos.

Palavras-chave: ensino de biologia, paráfrases, semiologia.

\section{PARAPHRASES: A GENUINE WAY OF MEANING APPROPRIATION IN ECOLOGY TEACHING}

Abstract: This paper shows a biology teaching strategy, which uses the paraphrase, to promote appropriations of the concept of energy and material in ecosystems. The paraphrase is presented as a form of appropriation of speech by the subject, which has the autonomy to modify the scientific concepts in a singular way and maintain the similarity of both. This article sustains on elements of semiology focused on science education, more specifically in the written register of language. A teaching practice was constructed and applied with third grade students in the biology discipline, into three classes, and each student has produced three activities. The paraphrases were produced for five students and in this paper two of them were analyzed. The results indicate that this teaching strategy can be useful for highlighting the student's repertoire and promoting to take ownership of cognitively key concepts in Science. The activity may also provide criteria for teachers to avoid stereotyped answers by students.

Keywords: biology teaching, paraphrase, semiology. 


\section{INTRODUÇÃo}

Para o ensino de ciências, não podemos considerar que se aprende uma categoria ou um conteúdo como se apreende uma habilidade intelectual qualquer (VYGOTSKY, 2009). Um conceito científico está permeado da descrição prática de um fenômeno com a tentativa de sua generalização, em diversos níveis de complexidade. Isso exige não apenas a descrição do conceito, mas também no que é aplicável e onde se delimita. Verifica-se no ensino de biologia uma insistente utilização de categorias e vocábulos nas aulas que direciona o estudante a aprender por repetição e memorização (KRASILCHIK, 2000). A tentativa de empregar esse conhecimento em uma reflexão real pode acabar frustrada, manifestando a impotência de articulá-lo em outros momentos.

Assim, a ciência cognitiva, com sua atenção voltada ao processo do pensamento e da linguagem, não pode ser vista dissociada de um modo de conceber e ensinar ciências. Portanto, é responsabilidade de todos os que acreditam em um viés reflexivo, que promovam mudança de práticas que insistem em reproduzir conteúdos e que por outro lado pensem na educação científica como algo contínuo, que prepara os educandos para o mundo moderno (KRASILCHIK; MARANDINO, 2007). Castro (2005) aponta que já no Séc. XIX a forma de conceber o ensino oscilava entre duas vertentes: uma com ênfase no método, para executar um caminho do não saber para o saber; e a ênfase no sujeito, que deveria ser motivado, convencido a aprender pela curiosidade. Podemos comparar que esta ênfase no método, também presente na formação técnica, coaduna com uma postura de conceber a ciência e o ensino, e que ainda é muito presente nos dias atuais, como uma forma de "modelagem/armazenagem" (CASTRO 2005).

Frente ao contexto político-econômico em que a sociedade se encontra no qual as descobertas científicas ocupam papel de destaque e vultosos recursos são direcionados para promover uma intensa atualização tecnológica, há uma demanda de que os produtos das ciências sejam compreendidos pelas novas gerações, em um sentido de alfabetização científica (CACHAPUZ et al., 2001). Entretanto, mesmo com o aumento dos produtos tecnológicos em nosso cotidiano, Cachapuz et. al. (2001) argumentam que aprender ciências ainda apresenta um alto grau de rejeição pelos estudantes. Essa contradição - a necessidade de aprender ciências e sua rejeição - é um dos argumentos para que sejam construídas alternativas pedagógicas com bases 
epistemológicas coerentes e interessantes para os alunos, e em adição, objetivar ainda um ensino que promova uma aprendizagem que seja significativa (MOREIRA, 1999).

Quando Vygotsky (2009) enfatiza que um ensino tradicionalista, que intenta transmitir diretamente conceitos se mostra pedagogicamente estéril, com assimilação vazia de palavras, esse tipo de ensino pode gerar falsos resultados por imitação, cópia ou memorização superficial, em que o conceito científico só se adequa ao momento da sala de aula e o aprendiz não consegue lhes dar significado e relacioná-lo aos fenômenos do mundo. Deste modo, inicialmente, os discursos surgem como uma forma de comunicação, que pode ser memorizado, e só depois como atividade de reflexão interior (VYGOTSKY, 2004), em que um aprendiz aprende a verificar e tomar consciência dos pressupostos de seu pensamento. Ao combinar um ensino contextualizado que organize atividades de reflexão, para Vygotsky (2004), a função de comunicação, uma etapa livre e desprendida, pode ser gradualmente substituída por momentos conceituados, em que essa fala encontra correspondência com determinados esquemas lógicos, de forma a serem internalizados. Para Luria (2010), esse momento da substituição da fala livre e comunicativa para uma de aprendizado conceituado não é espontâneo, o que exige do professor criação de estratégias de internalização do discurso.

A partir da necessidade de uma estratégia de estimule a internalização dos conhecimentos e assumindo que os conceitos científicos são mediados e concebidos como uma linguagem específica, Fang (2006) aponta critérios para apropriação desses conceitos. Ao utilizá-la para a construção de saberes, é necessário delimitar as diferenças com a linguagem cotidiana, já que a linguagem científica contém características léxicas, semânticas e sintáticas próprias, além de denotar significados, funções e elementos específicos (OLIVEIRA; MUNFORD, 2014). Esses autores argumentam em paralelo com Fang (2006) a respeito da diferença elementar entre a fala cotidiana e a científica. A primeira seria mais dinâmica e relaciona-se com sujeitos que interagem com ações e processos, já a segunda trabalha com conceitos abstratos, precisos e densos de significados.

Ao colocar em relevo a importância das especificidades da linguagem científica, é oportuna a reflexão acerca de como as representações dos conteúdos científicos são expressas, e para os objetivos de aprendizagem, apropriadas pelos estudantes. Segundo Duval (1999), o plano de expressão das representações ou semiósis passa se relaciona intimamente com o plano das 
representações mentais (DUVAL, 2006), do conteúdo, das apreensões conceituais, da noésis. Assim, o signo científico é entendido composto e relacionado com uma série de normas particulares para sua formação.

A formação de uma representação semiótica respeita regras próprias, que são definidas convencionalmente, para que o signo possa ser reconhecido no meio social. Dessa maneira, a representação é percebida, identificada, e assim, o aprendiz pode extrair o conceito representado e internalizá-lo cognitivamente (DUVAL, 1999). Uma das atividades possíveis depois da propriedade de formação de representações semióticas é o tratamento, quando se transforma internamente a representação de um dado registro semiótico, permanecendo no interior do mesmo registro de representação. O tratamento pode ser considerado como uma expansão, uma alteração da informação mantida em um mesmo registro semiótico. Considera-se como exemplos de tratamento, o manejo de dados internos na realização de cálculos dentro de um mesmo sistema ou o mecanismo da paráfrase na linguagem, em que se reformula uma proposição a respeito de um conteúdo, substituindo-o por outra proposição, mas em que permanece o mesmo significado (DUVAL, 1999).

Através de paráfrases, pretende-se promover um aprofundamento conceitual dos aprendizes, com possibilidade de o professor acompanhar o modo pelo qual que um estudante conceitua determinado conteúdo. Portanto, quando o estudante é solicitado a executar operações linguísticas de paráfrases, de fato está executando uma atividade semiótica de tratamento interno, com a possibilidade de orientar a apropriação de significados, convergindo com o que (VOLOSCHINOV, 1992) designa de compreensões genuínas, ou seja, o aprendiz ao compartilhar uma resposta orientada em relação ao contexto da enunciação ensinada faz com que a cada palavra da enunciação que estiver em processo de compreender corresponda uma série de palavras próprias. Quanto mais numerosas e substanciais forem estas últimas, mais profunda e real será sua compreensão (VOLOSCHINOV, 1992).

O desenvolvimento de uma estratégia didática com o uso de paráfrases parte da intenção, portanto, de promover uma de aprendizagem que compartilhe significados entre o professor, seus estudantes e os textos científicos escolares, de modo que haja equivalência de sentidos, ainda que as sentenças construídas sejam diferentes em cada caso. Bakthin (1983) indica que essa 
autonomia do discurso provém dessa relação entre significados, e se torna correlato com a ideia geral de apropriação de Vygotsky (2004) da fala genuína, que necessita internalizar conceitos para que vão além de uma superficial verbalização.

Uma estratégia de aprendizagem centrada na produção de paráfrases pelos estudantes visa uma objetivação e produção de representações que construam sentenças, com o intuito de que o professor não seja iludido por pseudoentendimentos, que se encontram no plano da imitação. Muitas vezes, a mera imitação passa a ser valorizada pelo docente sem que existam critérios objetivos para que se reconheçam significados realmente compartilhados no processo de aprendizagem. Entende-se assim que qualquer entendimento verdadeiro é dialógico por essência no sentido colocado por acima por Bakthin, que quanto mais palavras de repertório próprio do aprendiz preservando o conceito científico, mais profunda é a compreensão. 0 emprego didático de paráfrases pode ser uma etapa do processo de aprendizagem e ensino, que permite o estudante compartilhar respostas orientadas em relação aos enunciados - do professor e do livro didático - que lhes foram apresentados.

Ao focar no discurso verbal escrito e utilizar estratégias de aprendizagem fundamentadas no tratamento de registros semióticos, o estudante deve modificar o enunciado inicial ensinado, parafraseando-o de modo a manter o mesmo significado dos conceitos apresentados. Assim, um enunciado científico já estabelecido pode não apenas ser copiado ou memorizado, mas expandido ou condensado para que se exprimam suas possibilidades, evidenciando formas adequadas de expressão. Um estudo realizado na área do ensino de física, utiliza as relações sintagmáticas e paradigmáticas da língua, em que o estudante associa termos sublinhados com outros equivalentes e rearranja o conceito inicial de modo a expressar de forma coerente o conceito (LABURÚ; BARROS; SILVA, 2013). A presente prática teve com um de seus objetivos expandir a ação do aprendiz ao utilizar a paráfrase, de modo que seja possível utilizar elementos que não estão no conceito inicial e propiciar mais liberdade e estimular a criatividade do aluno.

Dentro da definição do que é paráfrase, Wenzel (apud. HILGERT, 1997) designa de paráfrases reconstrutivas as que refazem um dado conteúdo mantendo suas equivalências semânticas. Esse tipo de paráfrase pode ser utilizado por um ouvinte para reformular o enunciado de outra pessoa, com o uso de outros léxicos, ampliando e mostrando capacidade de compreensão. Sant'Anna 
(1985) indica que a paráfrase é a história da invenção e da descontinuidade, e não da repetição, pois o corte e a ruptura são marcas dos estudos que marcam diferença entre o velho e o novo e acrescentam algo ao que já foi construído. Nesse sentido, o mecanismo da paráfrase é constituinte do desenvolvimento das ideias, que aumentam e dialogam com novos sentidos.

Para Medeiros (2006) existem cinco tipos de paráfrase: a reprodução, o comentário explicativo, o resumo, o desenvolvimento e a paródia (MEDEIROS, 2006). A reprodução é o ato de reescrever de modo direto ou indireto ideias literais de um texto com palavras distintas; o comentário explicativo é usado para argumentar e reexplicar ideias de um texto original; o resumo é a condensação dos conteúdos tratados; o desenvolvimento é o modo de expandir o conteúdo do texto, ao associar ideias novas e exemplos; e a paródia uma forma de satirização.

Comum a esses autores e proveitoso para a aprendizagem de ciências é a perspectiva das paráfrases e associações para reconstruir a mesma ideia com outras palavras que não a literal do professor, dos lidos nos livros didáticos ou encontrados em outros meios. Os critérios da paráfrase, que estabelecem relações semânticas equivalentes entre os enunciados, baseiam-se na forma com que os aprendizes possam ser criativos e simultaneamente resguardar correspondentes com critérios científicos válidos. Com a modificação dos registros, esta estratégia de aprendizagem que se utiliza de paráfrases visa uma objetivação e produção de representações que construam paráfrases autênticas, com o intuito de que o professor tenha uma maior garantia do que os alunos compartilhem conteúdos genuínos.

Ao utilizar-se da paráfrase como uma estratégia e critério analítico de aprendizagem, pretendemos analisar e discutir os significados compartilhados pelos estudantes, dentro de uma proposta exequível para docentes de Ensino Médio no tempo regular de suas aulas. Mais do que verificar se as respostas foram corretas ou erradas, o grande objetivo é o de elaborar uma proposta que forneça dados relevantes sobre a compreensão de dado assunto e possibilitar intervenções posteriores dos docentes.

\section{METODOLOGIA E AMBIENTE DE PESQUISA}

A pesquisa tem natureza qualitativa de cunho interpretativo e toma a paráfrase, na análise das produções escritas em atividades de ecologia. $O$ trabalho teve um viés exploratório, que de acordo 
com Gil (1999), distingue-se por abordar, introduzir ou modificar conceitos para estudos posteriores.

Para o desenvolvimento da pesquisa, houve uma integração do conteúdo com o planejamento realizado pelo professor regente, dessa forma, não se alterou a sequência já previamente elaborada. Com autorização da Unidade de Ensino para a realização das atividades, foi apresentado aos estudantes a proposta e quais seriam as atividades realizadas. Houve a garantia de que suas identidades seriam preservadas de modo a não serem identificados e a turma aceitou participar da proposta.

Foi escolhido em conjunto pelo pesquisador e professor regente o conteúdo de cadeia alimentar e fluxo de energia, por melhor adequação de calendários. Solicitou-se que o professor mantivesse seu modo habitual de desenvolvimento das aulas, com conversas semanais entre ambos para dialogar sobre a aula e o quanto avançou o conteúdo preestabelecido. As aulas de Biologia ocorreram duas vezes por semana, em dias distintos, e o pesquisador lecionou uma aula sempre posterior a do professor regente. Ao total, foram três aulas em um intervalo de três semanas, com os estudantes executando três paráfrases ao final de cada aula do pesquisador. As aulas aconteceram no 3ำ ano do Ensino Médio de um colégio público da cidade de Londrina, com uma turma de onze estudantes. Ao todo, apenas cinco estudantes foram analisados porque cumpriram os critérios de realizar as três atividades.

Próximo ao final da primeira aula em que o pesquisador estava, executou-se em conjunto com a turma paráfrases de frases cotidianas, de modo que o sentido geral estivesse preservado. Após esse momento, iniciaram-se as orientações para a paráfrase do conceito apresentado. As instruções dadas era de que o estudante substituísse ao máximo os termos da frase e sua ordem. Assim, estaria livre para reescrever do modo como desejasse a frase inteira apresentada. Foi discutido que a frase representava um conceito-chave das duas últimas aulas dadas. É importante salientar a orientação de que os estudantes modificassem quaisquer termos, mesmo que alterassem a concordância de gênero e de número originais, desde que fossem equivalentes e preservassem o sentido geral proposto. Outra orientação foi que as quatro linhas do papel poderiam ser extrapoladas ou não serem completadas. Havia uma tendência dos estudantes completarem rigidamente as quatro linhas, aumentando a letra ou a distância entre as palavras. 
Perucci e Laburú, 2016 - Ensino de Ciências e Matemática

Isso fez com que imediatamente os estudantes realizassem a atividade de modo mais livre, sem que necessitassem completar a todo custo o espaço destinado. O tempo destinado para a produção de cada paráfrase foi por volta de 10 minutos.

Os três enunciados que foram parafraseados, em sequência, foram:

"A quantidade de energia presente em um nível trófico qualquer sempre será maior que a quantidade de energia do nível trófico posterior." (AMABIS, J. M. MARTHO, 2009)

"Quanto menos níveis tróficos uma cadeia alimentar apresentar, menor será a dissipação energética ao longo dela, uma vez que as maiores perdas de energia acontecem, precisamente, na transferência de matéria orgânica de um nível trófico para outro". (RICKFLESS, 2003)

"Os produtores representam a "porta de entrada" da energia no mundo vivo. Por isso, o fluxo energético desenvolve um trajeto no sentido produtores, para os consumidores e por fim decompositores (PAULINO, 2002)."

Eles ficaram olhando as frases ou tiveram que parafrasear sem olhar?

Os tipos de paráfrases elencados por Medeiros (2006) que foram consideradas foram as de quatro tipos: (resumo, comentário explicativo, desenvolvimento e reprodução). Elas serviram de base para a análise das paráfrases produzidas. Dentro da proposta geral da atividade, as paráfrases que se utilizaram de um comentário explicativo, ao reescrever trechos específicos que melhoram a compreensão, e as de desenvolvimento que ampliam o conteúdo ali descrito, foram consideradas como mais favoráveis para a apropriação de conceitos desta atividade. O resumo que condensa informações e a reprodução (desde que tenha alteração das palavras) diminui a abundância de termos, e por consequência, mostra um menor repertório do estudante sobre o tema. Assim, a meta de aumentar e a diversificar as informações foram consideradas como mais propícias a se aproximar do compartilhamento de significados.

Para as aulas que foram ministradas antes das paráfrases foram utilizadas uma ampla variedade de figuras, esquemas, tabelas, gráficos, em suma, vários registros de representações semióticas que os conteúdos de biologia e em especial os de ecologia já comumente trazem. A dinâmica de todas as aulas foi baseada na metodologia de alternância do discurso univocal e de autoridade e o dialógico, variando ocasiões de perguntas abertas e momentos dirigidos para a definição de 
Perucci e Laburú, 2016 - Ensino de Ciências e Matemática

conceito. Essa metodologia é elaborada no intuito de procurar o desenvolvimento de participações mais ativas no conhecimento elaborado (MORTIMER; MACHADO, 2000).

Para este trabalho, serão apresentadas as três produções de dois estudantes.

\section{ANÁLISE DOS RESULTADOS DO ESTUDANTE 1}

Figura 1. Primeira produção do Estudante 1 - Paráfrase 1.

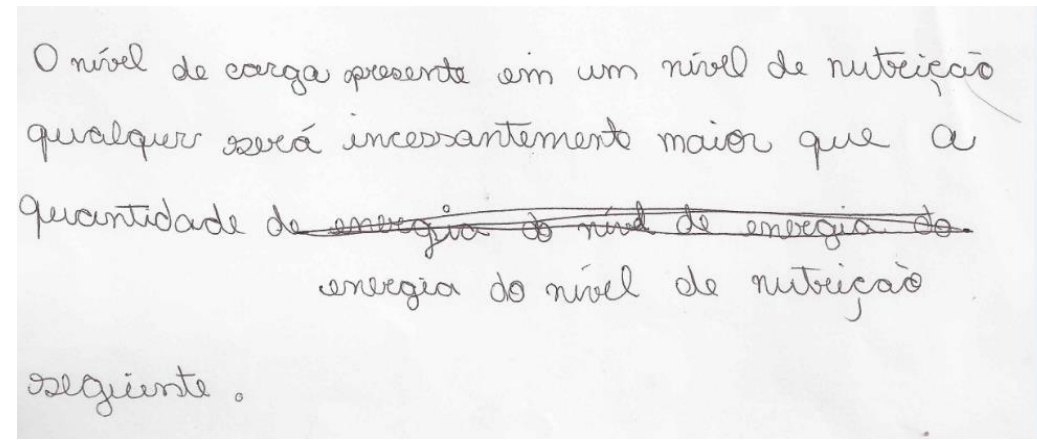

Fonte: dados da pesquisa.

Na elaboração da paráfrase 1, para o Estudante 1 não houve variação na ordem dos monemas presentes no enunciado-chave. $O$ estudante 1 associa poucos termos cognatos e não apresenta uma paráfrase que reelabore e faça equivalência semântica com outros termos. Na paráfrase o termo "carga", que ao ser substituído, não guarda relação com energia e, portanto, não permite compreender qual é o sentido original da frase. A palavra "Trófico" foi associada corretamente com "nível de nutrição", e a reescrita substituiu os dois momentos em que trófico aparecia no enunciado original.

De acordo com os tipos de paráfrase designados por Medeiros (2006), a paráfrase construída seria do tipo "reprodução", uma vez q o conteúdo é reproduzido literalmente de forma direta ou indireta. A ausência de exemplos para caracterizar "quantidade de energia" e "níveis tróficos", dois termos que poderiam ser substituídos por exemplos concretos, mostra que não houve condensação ou expansão do enunciado original. 
Figura 2. Paráfrase 2 do Estudante 1.

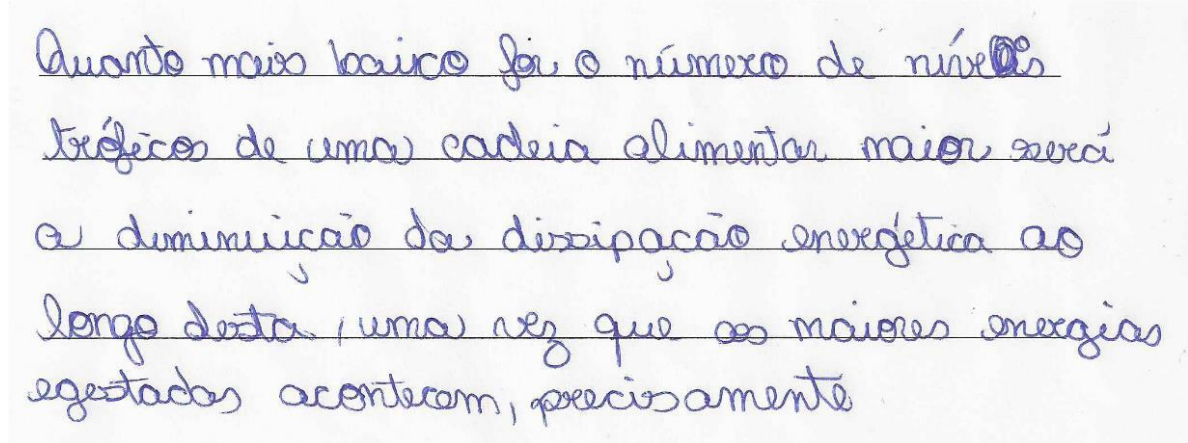

Fonte: dados da pesquisa.

A paráfrase 2 mostrou uma inversão de "menor dissipação" para "maior será a diminuição" que mesmo sendo uma construção prolixa está correta. O estudante reconstrói em parte o conceito ao conseguir manter o sentido da oração. A expressão "uma vez que..." que é de caráter causal, não tem seu raciocínio desenvolvido, já que foi interrompida. Vale notar o trecho "maiores energias egestadas" como incoerentes, pois o que é egestado não tem relação quantitativa de maior ou menor energia perdida com o nível trófico que tal animal ocupa, podendo ocorrer em qualquer nível.

Seguindo os critérios de equivalência semântica das paráfrases, e que ao alterar o registro de representação semiótica via tratamento, a produção final não permite compreender qual a ideia do enunciado original. A ausência de correspondência semântica não nos permite classificar a paráfrase dentro das acepções de Medeiros (2006).

Figura 3. Paráfrase 3 do Estudante 1.

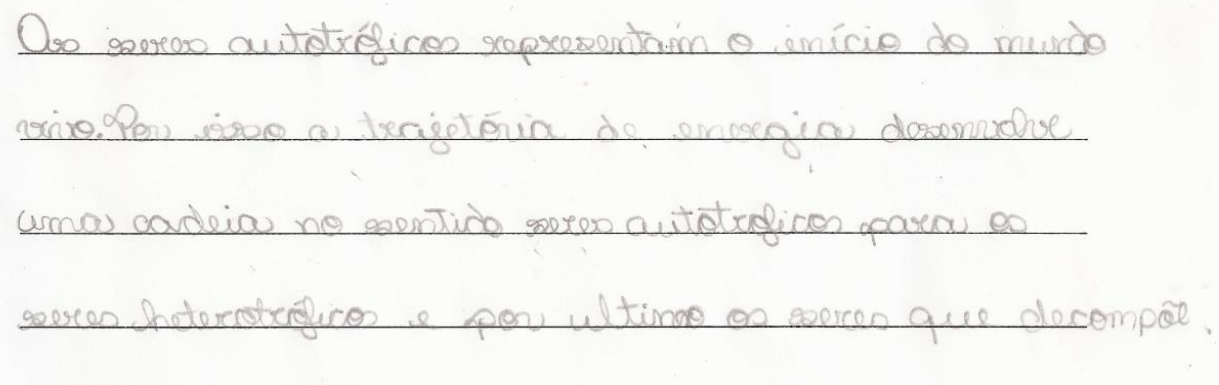

Fonte: dados da pesquisa.

A paráfrase 3 do estudante reelaborou de maneira adequada o conceito. Foram realizadas substituições dos termos sublinhados na primeira atividade, mantendo a mesma sequência da ordem da frase original. Essa paráfrase do tipo reprodução mantém a equivalência semântica com 
o conceito-chave e apenas substitui os monemas que já haviam sido indicados. Todos os conceitos associados são similares e correspondentes.

\section{ANÁLISE DOS RESULTADOS DO ESTUDANTE 2}

Figura 4. Paráfrase 1 do Estudante 2.

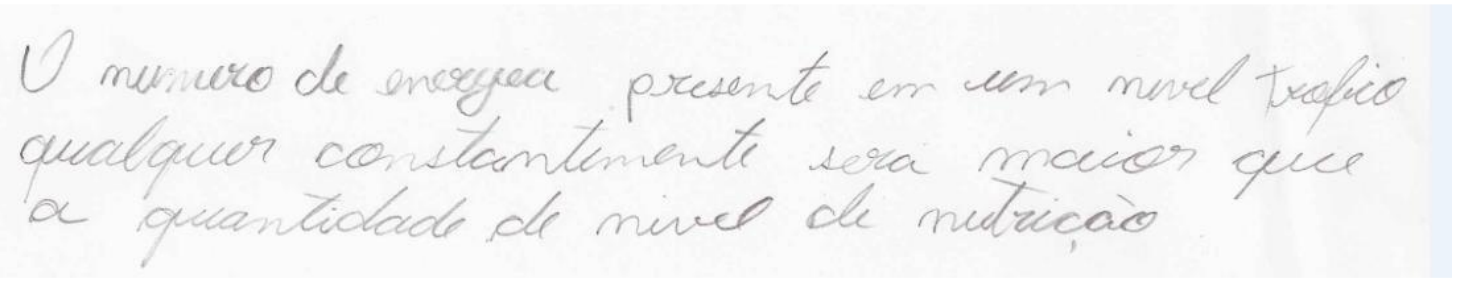

Fonte: dados da pesquisa.

Na elaboração da paráfrase 1, o estudante utilizou elementos muito semelhantes ao enunciado original, com uma substituição acertada de nível "trófico" para nível de "nutrição". N não houve a descrição da relação do nível nutrição em comparação com o outro "qualquer", mostrando uma incompletude da ideia.

A paráfrase 1 possuiu uma construção muito semelhante ao enunciado original proposto, realizando um tratamento com a mesma ordem extensiva dos monemas do enunciado-chave original, caracterizando-se como um tipo paráfrase de reprodução.

Figura 5. Paráfrase 2 do Estudante 2.

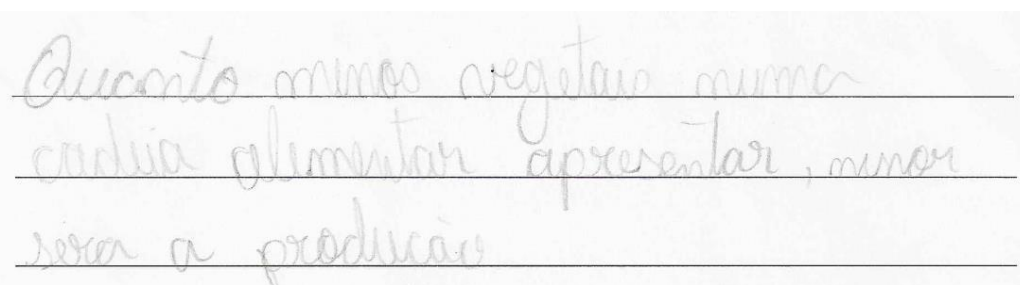

Fonte: dados da pesquisa.

$\mathrm{Na}$ elaboração da paráfrase 2, o estudante associa os níveis tróficos com um único exemplo "vegetais", construindo um enunciado que relaciona menor produção com uma menor quantidade de vegetais. "Produção" nesta paráfrase não é utilizada com seu significado científico, e o estudante faz relações que compare "menos vegetais a uma menor produção". A reescrita do conceito condensou e se modificou em relação ao original, não sendo possível inclusive, caso se 
observe apenas a paráfrase 3, apreender quais eram os significados da frase inicial, caracterizando como um tipo de resumo.

Figura 6.Paráfrase 2 do Estudante 2.

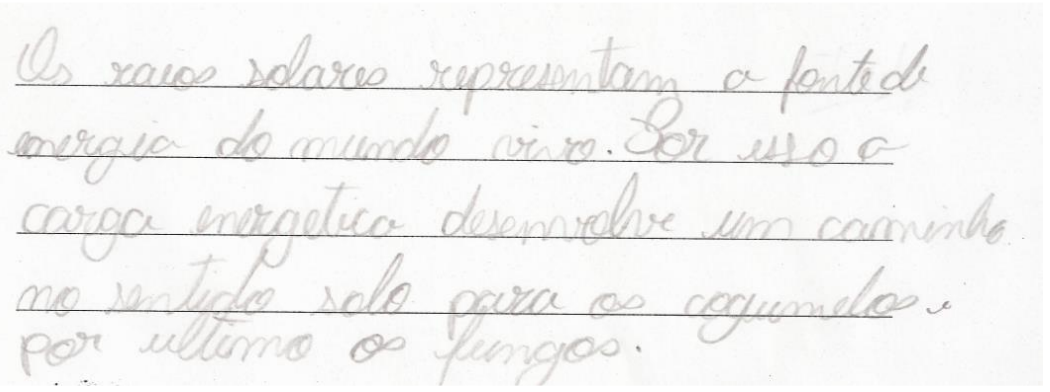

Fonte: dados da pesquisa.

O estudante 2 mantém a mesma estrutura do enunciado-chave, apenas alterando os termos nos quais associou outros para a produção anterior. Na elaboração da paráfrase, o estudante mostra na primeira parte até "mundo vivo" uma grande reorganização do enunciado ao reorganizar e condensar o conteúdo. Ao dizer que os "raios solares representam a fonte de energia do mundo vivo", faz uma correta generalização da influência da energia luminosa como base da imensa maioria de cadeias alimentares existentes. A segunda parte que se inicia com "por isso" apresenta incompreensões na relação com "solos" e "cogumelos", designados como representantes dos níveis tróficos "produtores" e "consumidores", e por último, os fungos como decompositores. O aumento das informações originais caracteriza essa paráfrase como um tipo de desenvolvimento.

\section{CONCLUSÕES}

A perspectiva de investigar novas abordagens na forma representacional escrita com base na teoria da semiologia direcionada a aprendizagem de ciências teve como objetivo estabelecer formas mais precisas do docente refletir e intervir nas apropriações de conceitos científicos, no caso, do Ensino de Biologia. Podemos analisar o repertório do estudante a respeito de cada termo, dentro de seus limites expansivos e contingenciais e utilizá-los para constatar como a estrutura linguística da paráfrase ajuda a inscrever novos significados de modo a condensar ou expandir os conceitos-chave.

A definição de conceitos elementares de cada unidade didáticas podem evidenciar critérios para o professor averiguar as apropriações dos conteúdos. O material produzido, de um modo simples e 
consoante com a realidade do tempo disponível dos docentes, dá subsídios para alterar conceitos impróprios em assuntos que podem novamente ser abordados com as turmas.

Nos resultados apresentados, a grande maioria das paráfrases analisadas são dentro da categoria de Medeiros as de reprodução, o que evidencia uma menor criatividade e a manutenção de tarefas com respostas estereotipadas. A mobilização de mais registros em uma atividade orientada traz mais elementos para o docente propor distintas formas de representação que podem enriquecer o vocabulário e a compreensão, com fins para a alfabetização científica. Por fim, maneiras de modificar o registro escrito são presentes em vários programas de pesquisa, com outras denominações e objetivos imediatos, mas que confluem para a melhora da interpretação e escrita dos estudantes. Esse trabalho pretendeu se inserir em mais uma dessas contribuições.

\section{REFERÊNCIAS}

AMABIS, J. M.; MARTHO, G. R. Biologia. 1 ed. São Paulo: Moderna, 2009.

BAKHTIN, M. Questões de literatura e estética: a teoria do romance. 3 ed. São Paulo: Hucitec/UNESP, 1983.

CACHAPUZ, A. A emergência da didática das ciências como campo específico de conhecimento. Revista Portuguesa de Educação, v. 14, n. 1, p. 155-195, 2001.

CASTRO, A. D. A Trajetória Histórica da Didática. 1 ed. São Paulo: FDE, 2005.

DUVAL, R. Semiosis y pensamiento humano: registros semióticos y aprendizajes intelectuales. 1 ed. Cali: Universidad del Valle, 1999.

DUVAL, R. A. Cognitive Analysis of Problems of Comprehension in a Learning of Mathematics. Educational Studies in Mathematics, v. 61, n.1, 103-131, jul. 2006.

FANG, Z. The language demands of science reading in middle school. International Journal of Science Education, v.28, n.5, p. 491-520, 2006.

GIL, A. C. Métodos e técnicas de pesquisa social. 1 ed. São Paulo: Atlas, 1999.

HILGERT, J. G. Procedimentos de reformulação: a paráfrase. In: PRETI, Dino. (Ed.). Análise de textos orais. 3 ed. São Paulo: Humanitas, 1997.

KRASILCHIK, M. Reformas e realidade: o caso do ensino das ciências. São Paulo em Perspectiva, v. 14, n. 1, p. $85-93$ 2000.

KRASILCHIK, M; MARANDINO, M. Ensino de ciências e cidadania. 2 ed. São Paulo: Moderna, 2007.

LABURÚ, C. E; BARROS, M. Alves; S, Osmar. Construção dos conceitos de física de estudantes apoiada em relações sintagmáticas e paradigmáticas. Acta Scientiae, v.16, n. 1, p. 93-113, jan/abr. 2014.

LURIA, A. R. Desenvolvimento Cognitivo. 1 ed. São Paulo: Cone, 2010.

MEDEIROS, J. B. Redação científica: a prática de fichamentos, resumos, resenhas. 8 ed. São Paulo: Atlas, 2006. 
MOREIRA, A, M. Aprendizagem significativa. 1 ed. Brasília: Editora Universidade de Brasília, 1999.

MORTIMER, E. F.; MACHADO, A. H. Anomalies and conflicts in classroom discourse. Science Education, v.84, n. 1, p. 429-444, 2000.

RICKFLESS, R. E. A economia da natureza. 5 ed. São Paulo: Guanabara Koogan, 2003.

SANT'ANNA, A. F. Paródia, paráfrase \& Cia. 3 ed. São Paulo: Ática, 1985.

PAULINO, W. R. Biologia Atual. 1 ed. São Paulo: Ática, 2002.

VOLOSCHINOV, V. N. Marxismo e Filosofia da linguagem. 1 ed. São Paulo: Hucitec/UNESP, 1992.

VYGOTSKY, L. S. Psicologia Pedagógica. 1 ed. São Paulo: Martins Fontes, 2004.

VYGOTSKY, L. S. A construção do pensamento e da linguagem. 1 ed. São Paulo: Martins Fontes, 2009. 